\title{
TEORIAS DESCRITIVISTAS DOS NOMES PRÓPRIOS
}

Claudio F. Costa

UFRN-CNPq

\begin{abstract}
The main aim of this paper is interpretative. I will expose the traditional descriptivist theories of proper names suggested by Frege, Russell, Wittgenstein and Searle, showing that, differently from what is usually thought, they are not competitive theories, but only somewhat diverse presentations of a particular view.
\end{abstract}

Keywords: Proper names, descriptivism, meaning, philosophy of language.

Resumo: 0 principal objetivo desse artigo é interpretativo. Trata-se de historiar as tradicionais teorias descritivistas dos nomes próprios sugeridas por Frege, Russell, Wittgenstein e Searle, demonstrando que, diversamente do que é suposto, elas não constituem teorias diversas a competir entre si, mas apresentações algo diversas de um mesmo modo de ver.

Palavras-chave: Nomes próprios, descritivismo, significado, filosofia da linguagem.

A teoria descritivista dos nomes próprios dominou o século $\mathrm{XX}$ até a década de 1970, quando foi em parte eclipsada pela concepção históricocausal de Saul Kripke, Keith Donnellan e outros. A idéia geral do teoria descritivista é a de que o nome próprio refere indiretamente, por uma alusão a propriedades geralmente exprimível através de conjuntos de descrições.

Segundo uma interpretação corrente, há duas formas de descritivismo: uma mais primitiva, defendida por Frege e Russell, segundo a qual o sentido de um nome próprio é dado por uma única descrição definida associada a ele, e uma sofisticada, defendida por filósofos como Wittgenstein, Strawson e Searle, segundo a qual o sentido do nome próprio é dado por um feixe ou 
agregado de descrições ${ }^{1}$. Quero demonstrar nesse artigo que essa interpretação é incorreta. Uma complexa teoria descritivista dos nomes próprios já era aludida nos escritos de Frege e Russell, embora lá se encontre fragmentariamente apresentada. $O$ que houve desde então foi uma progressiva explicitação e adição de detalhes por outros filósofos.

\section{Frege e Russell}

Comecemos com a formulação fregeana. Quando considera a questão da referência dos nomes próprios, Frege interpreta os seus sentidos como exprimíveis por diferentes descrições ou conjunções de descrições que a ele associamos. Como ele escreve em uma conhecida nota de seu artigo "Sobre sentido e referência”, onde a teoria descritivista propriamente se origina:

No caso de nomes genuinamente próprios, como 'Aristóteles', opiniões sobre o seu sentido podem divergir. O seguinte sentido pode ser sugerido: discípulo de Platão e tutor de Alexandre o Grande. Quem quer que aceite esse sentido irá interpretar o sentido do enunciado "Aristóteles nasceu em Estagira" diferentemente de quem interpreta o sentido de Aristóteles como o professor estagirita de Alexandre o Grande. $\mathrm{Na}$ medida em que o nominatum permanece o mesmo, essas flutuações no sentido são toleráveis. ${ }^{2}$

Mesmo que as descrições escolhidas preservem a univocidade da referência, as flutuações no sentido não podem ser tão grandes a ponto de impedir a comunicação. Se duas pessoas associam descrições totalmente diferentes a um nome próprio, perde-se a unidade do sentido e torna-se impossível para elas saberem se estão falando da mesma pessoa. Este ponto é também notado por Frege. Suponha, diz ele, que Leo Peter tenha ido à residência do doutor Gustav Lauben e o tenha ouvido dizer "Eu fui ferido", isso sendo tudo o que ele sabe sobre Gustav Lauben. Leo Peter tenta comentar o ocorrido com Herbert Garner, que por sua vez sabe de um Dr. Gustav Lauben que nasceu em 13 de setembro de 1875 em N.N., não sabendo, por sua vez, onde o Dr. Lauben reside agora nem qualquer outra

\footnotetext{
1 Ver Michael Devitt e Kim Sterelny: Language and Reality: An Introduction to the Philosophy of Language, p. 45. Ver também W. G. Lycan: "Names", pp. 256-7.

2 G. Frege: "Über Sinn und Bedeutung", p. 28 (paginação original).
} 
coisa sobre ele. Disso resulta que Leo Peter e Herbert Garner não conseguem saber se estão falando da mesma pessoa. Pois segundo Frege eles

não falam a mesma língua, ainda que com esse nome eles de fato designem o mesmo homem; pois eles não sabem que fazem isso. Herbert Garner não associa, pois, à frase "Dr. Gustav Lauben foi ferido", o mesmo pensamento que Leo Peter quer com ela exprimir. ${ }^{3}$

Dessa espécie de discussão deixa-se facilmente concluir que Frege concordaria com a tese descritivista de que o sentido completo de um nome próprio é constituído por um conjunto de valores cognitivos (sentidos) geralmente exprimíveis através de descrições; cada falante tem geralmente acesso a um subconjunto desse conjunto de valores cognitivos; mas esse acesso precisa ter em comum ao menos o suficiente para que os falantes possam saber que estão falando da mesma coisa. É preciso que os dois conjuntos de descrições pelo menos se interseccionem.

Michael Dummett, o mais importante intérprete de Frege, protestou contra a idéia de que este último teria proposto uma teoria descritivista dos nomes próprios ${ }^{4}$. Dummett alega que Frege usou descrições porque eram maneiras fáceis de esclarecer o sentido de alguns exemplos. Mas isso não tem nada a ver com a idéia de Russell de que o nome próprio é a abreviação de uma descrição complexa nem com a sua teoria referencial do significado. Além disso, escreve Dummett, não há nenhum indício de que Frege concordaria com a idéia de que o sentido do nome próprio possa ser sempre expresso através de descrições. Segundo ele, o importante para Frege é que o nome próprio seja associado a um critério para reconhecer um dado objeto como o seu referente. Dummett ilustra o seu ponto considerando as inúmeras maneiras possíveis de se identificar o rio Tâmisa ${ }^{5}$. Muitas vezes, escreve ele, isso é feito indiretamente, a partir de informações colaterais, como é o caso de uma pessoa que percebe que se trata do mesmo rio que

\footnotetext{
${ }^{3}$ G. Frege: "Der Gedanke", pp. 64, 76.

${ }^{4}$ Autores norte-americanos, influenciados por Saul Kripke, associam Frege ao descritivismo, enquanto autores ingleses, influenciados por Michael Dummett, costumam rejeitar essa associação. Ver M. Dummett: Philosophy of Language, pp. 97-98, pp.110-111. Ver também The Interpretation of Frege's Philosophy, p. 186 ss. Corroborando a interpretação de Dummett estão Leonard Lynski: Names and Descriptions, pp. $42-43$ e, mais recentemente, Michael Luntley, Contemporary Philosophy of Thought: Truth, World, Content, p. 261.

${ }^{5}$ M. Dummett: Frege: Philosophy of Language, pp. 97-98, 101-111.
} 
passa sob a ponte de Radcot ou através da cidadela de Henley. E uma pessoa pode saber que ele passa por Oxford sem saber que ele é o mesmo rio que atravessa Londres, ainda assim identificando o rio corretamente. Não há, conclui ele, nenhuma condição suficiente que todos precisem saber para a identificação do Rio Tâmisa.

A meu ver, nenhuma das razões aduzidas por Dummett justifica o seu protesto. Primeiro, é obviamente possível adotar o descritivismo sem se comprometer com uma teoria referencial do significado. Depois, nenhum descritivista pretendeu defender que tudo pode ser expresso por meio de descrições. Representações táteis, visuais e auditivas, nunca são totalmente resgatáveis em palavras. Descrições são apenas formas lingüísticas mais típicas, pelas quais valores cognitivos assomam à linguagem. $\mathrm{E}$ o que realmente conta são as regras semântico-criteriais que as descrições exprimem, as quais de algum modo servem para vincular o nome próprio ao seu portador. Esse entendi-mento, porém, é complementar à própria idéia de Dummett de que o importante para o sentido do nome próprio é que ele seja associado a um critério de identidade para o objeto, permitindo que ele seja reconhecido outra vez como sendo o mesmo ${ }^{6}$. Penso que Dummett tinha uma visão demasiado restritiva do que pode ser uma teoria descritivista dos nomes próprios, o que ficará mais claro quando compararmos o seu exemplo com o exemplo de Russell sobre Bismark.

Passemos agora à concepção de Russell. Como já foi notado, ele via os nomes próprios da linguagem ordinária como descrições definidas abreviadas, truncadas ou disfarçadas, sugerindo que eles pudessem ser analisados pelo mesmo método pelo qual ele analisara as descrições definidas. Como ele não estava primariamente interessado na prática lingüística ordinária, ele pouco se deteve na questão. Mas o nome próprio não abrevia uma única descrição, como muitos interpretam e como o próprio Russell, por mera conveniência de exposição, costuma colocar em seus textos mais técnicos. Em Os Problemas da Filosofia, porém, ele demonstra possuir um entendimento muito mais complexo da questão. Eis uma passagem:

Palavras comuns, mesmo nomes próprios, são geralmente descrições. Isto é, o pensamento na mente de uma pessoa usando um nome próprio corretamente em geral só pode ser expresso explicitamente se o substituirmos por uma descrição. Mais além, a descrição requerida para exprimir o pensamento

${ }^{6}$ Idem, ibidem, p. 73. 
irá variar para pessoas diferentes, ou para uma mesma pessoa em diferentes tempos. (grifos meus) ${ }^{7}$

O que essa passagem sugere é que há na linguagem um vasto repositório de informações sobre o objeto de um nome, as quais são exprimíveis na forma de descrições definidas. Quando proferimos o nome próprio, costumamos ter em mente uma ou mais dessas descrições, e tudo o que é necessário para que o ouvinte entenda que se trata da mesma pessoa, escreve Russell, é que ele saiba que as descrições se aplicam a mesma entidade evocada em sua mente ${ }^{8}$.

Russell apresenta como exemplo o nome 'Bismark'. Uma primeira e peculiar forma de acesso a Bismark é a que o próprio Bismark tem de si mesmo, em um juízo como "Eu sou Bismark". Nesse caso, realmente o próprio Bismark é um componente de seu juízo, sem passar por uma descrição. Uma outra maneira de se ter em mente Bismark é a das pessoas que lhe foram pessoalmente apresentadas. Nesse caso, o que a pessoa tem em mente é o corpo e a mente de Bismark, conhecidos por intermédio de conjuntos de sense-data a eles relativos, geralmente aptos a serem expressos por descrições. Ainda outra maneira de se conhecer Bismark, escreve Russell, é através da história. Nesse caso associamos a sua pessoa descrições como 'o primeiro chanceler do império germânico e um astuto diplomata’ (já uma descrição composta, formada pela conjunção de uma descrição definida com uma descrição indefinida). No final das contas, o que temos em mente é um vasto conjunto de informações históricas exprimíveis sob a forma de descrições capazes de identificar a pessoa univocamente. Como ele escreve:

Quando nós, que não conhecemos Bismark, fazemos um juízo sobre ele, a descrição em nossas mentes será provavelmente alguma mais ou menos vaga massa de conhecimento histórico muito mais, geralmente, do que é requerido para identificá-lo. Mas aqui, por razão de ilustração, vamos assumir que pensamos nele como 'o primeiro chanceler do império alemão'. (grifos meus) ${ }^{9}$

7 B. Russell: The Problems of Philosophy, p. 29.

8 Idem, ibidem, p. 30.

${ }_{9}$ Idem, ibidem, p. 30. 
O texto é do próprio Russell e não me deixa mentir. O que ele sugere é que quando usamos um nome próprio em terceira pessoa, o que temos em mente é uma descrição composta por uma variedade de outras descrições. Essa descrição possui contornos vagos (que costumam variar de usuário para usuário, e mesmo para um mesmo usuário), pertencendo a um ainda maior repositório de descrições que expressam informações identificadoras do mesmo objeto. Semelhante descrição composta pode ser analisada como uma conjunção de descrições sobre o mesmo x, ou seja, como uma conjunção de atribuições existenciais unívocas de propriedades. Se essas propriedades forem simbolizadas como as do conjunto $\{\mathrm{F} 1, \mathrm{~F} 2 \ldots \mathrm{Fn}\}$, a descrição definida composta, quando formada por outras descrições definidas, pode ser simbolizada como (Ex) ((F1x \& F2 x... \& Fnx) \& (y) ((F1x1 x1 = x) \& (F2x2 $\mathrm{x} 2=\mathrm{x}) \ldots \&($ Fnxn $\quad \mathrm{xn}=\mathrm{x})))$. A sugestão de que Russell pensava que ao usarmos nomes próprios temos em mente uma única descrição não passa, pois, de uma lenda.

O que essa interpretação textual também demonstra é que Russell está disposto a analisar o nome 'Bismark' de uma maneira que não difere substancialmente daquela pela qual Dummett analisa o sentido do nome 'Tâmisa'. Uma descrição central, como 'o primeiro chanceler do Império Germânico', é para Russell apenas uma dentre a massa de descrições que alguém pode associar a Bismark, da mesma forma que para Dummett a descrição central 'o rio que atravessa Londres' é apenas uma dentre as muitas descrições que alguém pode associar ao Tâmisa.

Se insistirmos em achar que Frege não foi um descritivista, então parece que deveremos concluir o mesmo de Russell. Mas como Russell é o nosso descritivista-mór, a conclusão só pode ser a de que Frege também foi um descritivista. E há uma razão para ser assim: se há uma unidade no objeto teórico, então as várias versões do descritivismo não devem ser alternativas inconsistentes entre si, mas aproximações mais ou menos congruentes de um mesmo fenômeno complexo, cada qual pondo em relevo diferentes aspectos seus, em tratamentos que podem divergir em métodos e em pressupostos filosóficos.

\section{Wittgenstein e Searle}

Após Frege e Russell, vários outros filósofos, principalmente Wittgenstein, P. F. Strawson e J. R. Searle, fizeram sugestões de interesse no 
sentido de aprimorar a teoria dos nomes próprios como feixes ou agregados de descrições. Quero considerar brevemente as sugestões de Wittgenstein e Searle.

$\mathrm{Na}$ seção 79 das Investigações Filosóficas Wittgenstein adiciona alguns comentários à concepção de Russell. Segundo ele, 'Moisés' poderia abreviar descrições como 'o homem que guiou os israelitas através do deserto', 'o homem que viveu naquele tempo e naquele lugar, e que naquela época foi chamado de 'Moisés", 'o homem que em criança foi retirado do Nilo pela filha do faraó' etc. Wittgenstein adiciona que o nome 'Moisés' ganha sentidos diferentes de acordo com a descrição que a ele associamos. A questão que emerge é: em que medida as descrições do feixe de descrições vinculadas ao nome precisam ser satisfeitas pelo objeto? Wittgenstein evade-se de uma resposta direta. Ele escreve apenas que nós utilizamos nomes próprios sem uma significação rígida, e que mesmo que algumas descrições falhem em se aplicar, ainda assim poderemos nos servir das outras como suporte. A linguagem natural é inevitavelmente vaga. E com o tempo o corpo de descrições identificadoras do objeto referido por um nome próprio pode variar: características que antes se afiguravam irrelevantes podem, em um conceito elaborado pela ciência, se tornar relevantes e convencionalmente aceitas, enquanto outras podem se enfraquecer ou serem rejeitadas... ${ }^{10}$

A formulação mais elaborada da teoria descritivista dos nomes próprios foi exposta por J. R. Searle em um artigo de 1958. Para esse autor, um nome próprio tem suas condições de aplicação definidas pela aplicação a um mesmo objeto de um suficiente, mas indefinido número de descrições. Searle exemplifica isso com o nome 'Aristóteles', que se encontra associado a uma classe de descrições definidas como 'o tutor de Alexandre o Grande', 'o autor da Ética a Nicômano, da Metafísica e De Interpretatione', 'o fundador da escola do Liceu em Atenas' e mesmo as descrições indefinidas como 'um grego' e 'um filósofo'. O nome próprio ‘Aristóteles' preserva a sua aplicação se um número suficiente e variável de tais descrições se aplica. Um número que minimamente se reduziria a uma disjunção de descrições.

Essa questão das condições de aplicação de um nome é também a do seu sentido. Na paráfrase sintética de Susan Haack: os sentidos que damos a

\footnotetext{
${ }^{10} \mathrm{~L}$. Linsky interpretou Wittgenstein como tendo sugerido a ausência de limites convencionais para fixar as descrições. Mas não há suficiente evidência textual para essa idéia. Seja como for, se Wittgenstein tivesse pensado assim ele estaria errado. Não parece concebível que os nomes próprios poderiam ter algum sentido e serem comunicacionalmente úteis se os limites de sua aplicação resultassem de decisão arbitrária. Ver L. Linsky, Names and Descriptions, p. 99.
} 
um nome próprio são expressos por subconjuntos não previamente determinados de um conjunto aberto de descrições co-referenciais ${ }^{11}$. O fato dos nomes próprios não conotarem sentidos específicos não quer dizer que eles não conotam sentido algum. Os nomes próprios conotam descrições de forma solta (in a loose way). Longe de ser um defeito, é isso o que dá ao nome próprio a sua imensa flexibilidade de aplicação. Como escreveu Searle:

...o caráter único e a imensa conveniência pragmática dos nomes próprios em nossa linguagem repousa precisamente no fato de que eles nos permitem referir publicamente a objetos sem sermos forçados a levantar questões e chegar a um acordo sobre que características descritivas exatamente constituem a identidade do objeto. Eles funcionam, não como descrições, mas como cabides para pendurar descrições. ${ }^{12}$.

Essa versão do descritivismo permite explicar uma variedade de casos. É possível, por exemplo, que um objeto satisfaça apenas umas poucas, ou mesmo uma única das descrições associadas ao nome próprio. $\mathrm{O}$ que não pode acontecer é que o nome próprio se aplique sem que nenhuma das descrições relevantes seja satisfeita. Como Searle notou:

Se um especialista em Aristóteles vier nos informar que descobriu que Aristóteles na verdade não escreveu nenhuma das obras a ele atribuídas, mas foi na verdade um mercador de peixes veneziano do renascimento tardio, nós entenderemos isso como uma piada de mau gosto e nos recusaremos a ver qualquer propósito no que ele está dizendo ${ }^{13}$.

De posse dessa teoria dos nomes próprios Searle tem condições de explicar afirmações de existência com nomes próprios, bem como identidades analíticas e não-analíticas entre eles: dizemos "O Everest existe" quando um número mínimo, mas indeterminado, de descrições, se aplica ao objeto. Afirmamos uma identidade analítica, como "O Everest é o Everest" quando os mesmos conjuntos de descrições de cada ocorrência do nome se aplicam ao mesmo objeto, e afirmamos identidades não-analíticas, como "O Everest é o

11 S.Haack: Philosophy of Logics, p. 58.

12 J. R. Searle: "Proper Names", Mind 1958, p. 171.

13 J. R. Searle: "Proper Names and Descriptions", p. 490. 
Chomolungma”, quando diferentes conjuntos de descrições se aplicam ao mesmo objeto ${ }^{14}$. Essas explicações estão em perfeito acordo com as de Frege15. Às duas últimas ele poderia adicionar que os conjuntos de descrições não podem ser disjuntos; se eles não forem idênticos, eles precisam ao menos se interseccionar para que saibamos que estamos falando de um mesmo objeto.

Embora Searle tenha desenvolvido a melhor versão de descritivismo em oferta, há objeções, boas ou más, contra ela. Uma boa objeção, proposta por William Lycan, é a seguinte ${ }^{16}$ : mesmo que o número de descrições satisfeitas pelo objeto não seja definido, ele precisa ser superior a metade do feixe de descrições, pois menos do que isso permitiria que dois objetos totalmente diversos, cada um satisfazendo uma metade das descrições, fossem identificados pelo mesmo nome próprio. Mas parece perfeitamente possível que se descubra um objeto que satisfaça menos da metade das descrições, talvez apenas uma ou duas, e mesmo assim seja referido pelo nome.

A resposta à objeção de Lycan é fácil de ser encontrada. Como todo critério de aplicação, o critério de satisfação parcial de um feixe de descrições tem seus limites de aplicação. Assim, se um objeto satisfaz metade das descrições e outro objeto satisfaz a outra metade, simplesmente não há mais como saber a que objeto devemos aplicar o nome próprio e ele perde a sua função referencial. Isso não impede, porém, a existência de casos nos quais apenas umas poucas descrições do feixe sejam satisfeitas e que isso seja suficiente para que o nome próprio se aplique: basta que não se conheça nenhum objeto concorrente que satisfaça um número tão grande de descrições identificadoras tão importantes quanto as já satisfeitas pelo suposto portador do nome próprio. Basta acrescentar a exigência da inexistência de concorrentes à altura para que a teoria de Searle continue válida.

$\mathrm{O}$ que esse breve excurso histórico a meu ver demonstra é que, diversamente do que se possa pensar, há uma forte unidade naquilo que os defensores do descritivismo tradicional sustentaram. Não se trata de várias teorias, mas de uma única, diversamente considerada por cada autor, o que parece falar algo a favor de seu potencial heurístico.

\footnotetext{
14 J. R. Searle: Speech Acts: An Essay in the Philosophy of Language, p. 171.

${ }^{15}$ Searle pensa que não porque ele interpreta erroneamente o exemplo de Frege de Herbert Garner e Leo Peter como exigindo que nosso aporte descritivo para o nome seja o mesmo. Mas não há nada na passagem de Frege a suportar essa afirmação. Ver J. Searle: Speech Acts, p. 169.

${ }^{16}$ W. Lycan: "Some Flaws in Searle's Theory of Proper Names".
} 


\section{Referências Bibliográficas}

DEVITT, M.; STERELNY, K. Language and Reality: An Introduction to the Philosophy of Language. 2.ed. Oxford: Blackwell, 1999.

DUMMETT, M. The Interpretation of Frege's Philosophy. London: Duckworth, 1981. . Truth and Other Enigmas. Harvard: Harvard University Press, 1978. . Frege: Philosophy of Language. 2.ed. London: Duckworth, 1981.

FREGE, G. "Sinn und Bedeutung". Zeitschrift für Philosophie und philosophische Kritik, NF 100, 1892.

. "Der Gedanke”. Beitrage zur philosophie des deutschen Idealismus I, 2, 1918, p. 58-77.

Lógica e Filosofia da Linguagem (ed. Paulo Alcoforado). Rio de Janeiro: Cultrix, 1978.

HAACK, S. Philosophy of Logics. Cambridge: Cambridge University Press, 1978.

LUNTLEY, M. Contemporary Philosophy of Thought: Truth, World, Content. Oxford: Blackwell, 1999.

LYCAN, W. "Names". In: DAVITT, M.; HANLEY, R. The Blackwell Guide to Philosophy of Language. Oxford: Blackwell, 2006.

LYCAN, W. G. "Some Flaws in Searle's Theory of Proper Names". Philosophy, 74, fall 2003.

LYNSKI, L. Names and Descriptions. Chicago: University of Chicago Press, 1977.

RUSSELL, B. “On Denoting”. Mind, 14, 1905, pp.479-493.

. The Problems of Philosophy. Oxford: Oxford University Press, 1980 (1912).

_-___. Introduction to Mathematical Philosophy. London: George Allen \& Urwin, 1919.

SEARLE, J. R. Intentionality. Cambridge: Cambridge University Press, 1983, p. 221. . "Proper Names", Mind, 67, 1958, p. 166-173.

. "Proper Names and Descriptions". In The Encyclopedia of Searle, J. R.

Speech Acts: An Essay in the Philosophy of Language. Cambridge: Cambridge University Press, 1969). Philosophy (Macmillan Publishers: London 1967), vol. 6, p. 490. 
STRAWSON, P. F. Individuals: An Essay on Descriptive Metaphysics. London: Methuen, 1959, parte I.

WITTGENSTEIN, L. Philosophische Untersuchungen (Investigações Filosóficas) Frankfurt: Suhrkamp, 1983, Werkausgabe Band.

E-mail: claudio.costa@pq.cnpq.br

Recebido: outubro/2009 Aprovado: novembro/2009 